\title{
SAÚDE DA MULHER: ESTUDO CITOLÓGICO E MICROBIOLÓGICO DO TRATO GENITURINÁRIO DE PACIENTES DO CENTRO DE PRÁTICAS SUPERVISIONADAS DA UNIVAP
}

\section{WOMEN'S HEALTH: CITOLOGIC AND MICROBIOLOGICAL STUDY OF GENITOURINARY TRACT IN PATIENTS OF THE SUPERVISED PRACTICE CENTER OF UNIVAP}

\author{
Ildelena Aparecida Godoy ${ }^{1}$ \\ Letícia Correa Fontana ${ }^{1}$ \\ Evelise F. Cordeiro ${ }^{2}$ \\ Sônia Khouri ${ }^{3}$ \\ Juliana Ferreira Strixino ${ }^{3}$
}

Resumo: O câncer de colo do útero ou cervical é o segundo tumor mais frequente na população feminina, antecedido pelo câncer de mama. Caracteriza-se como a quarta causa de morte de mulheres por câncer no Brasil, sendo as alterações celulares iniciais descobertas facilmente no exame preventivo, conhecido também como Papanicolaou. Este trabalho teve como objetivo desenvolver um estudo de rastreamento do câncer de colo uterino pelo exame de Papanicolaou e microbiológico no Centro de Práticas Supervisionadas (CPS) da UNIVAP, orientando as voluntárias sobre a saúde da mulher, explicando sobre os exames e a sua importância e sobre cuidados e prevenção desse tipo de câncer. Foram selecionadas 12 voluntárias, com idade entre 20 e 60 anos, para realização dos exames. Foram observadas alterações citológicas leves com quadro inflamatório, alterações nas células escamosas de significado indeterminado e, na análise microbiológica, observou-se a presença de leveduras. Conclui-se, com o presente resultado, a grande importância do exame e a proposta de mais um núcleo de referência para a sua realização.

Palavras-chave: colo do útero; Papanicolaou; microbiologia; citopatologia.

Abstract: Cervical cancer is the second most common tumor in women, preceded only by breast cancer. It is the fourth leading cause of cancer death in Brazilian women, and cellular changes are easily discovered with the Pap exam. This study aimed to develop a screening study of cervical cancer by Pap and microbiological analysis at the Supervised Practice Center (SPC) of UNIVAP, by educating volunteers about women's health and explaining the exams and the importance of care and prevention of this cancer. We selected 12 volunteers between 20 and 60 years old to be tested. Cytologic changes with mild inflammatory, changes in cell carcinoma of undetermined significance, and microbiological analysis showing the presence of yeast were observed. This result points to the importance of the Pap exam and the proposed survey is another reference for this realization.

Keywords: cervix; Pap; microbiology; cytopathology.

\footnotetext{
1 Graduanda em Biomedicina - Universidade do Vale do Paraíba - Univap. E-mails: ia.godoy@bol.com.br; leticia.fontana@yahoo.com.br.

${ }^{2}$ Graduada em Ciências Biológicas - Universidade de Mogi das Cruzes - UMC. E-mail: evelise_job@yahoo.com.br.

3 Docente da Univap. E-mails: soniak@univap.br; juferreira@univap.br.
} 


\section{INTRODUÇÃO}

O câncer de colo do útero, também chamado de cervical, é o segundo tumor mais frequente na população feminina, atrás, apenas, do câncer de mama, com 18.430 novos casos anuais. Atualmente, $44 \%$ dos casos são de lesão precursora do câncer, chamada in situ, enquanto, na década de 1990,70\% dos casos diagnosticados eram da doença invasiva, ou seja, o estágio mais agressivo da doença, o que demonstra um avanço na capacidade de realização de diagnósticos precoces do país (PINOTTI, 1994; HACKENHAAR; CESAR; DOMINGUES, 2006; WORLD HEALTH ORGANIZATION, 2006; INSTITUTO NACIONAL DE CÂNCER, 2010).

A relação entre o câncer cervical e a infecção por HPV é bem estabelecida. O DNA do HPV de alto risco é detectado em cerca de 92,9\% a 99,7\% dos casos de câncer cervical invasivo (RAMA et al., 2008). A infecção é condição necessária, porém não suficiente para o desenvolvimento do câncer cervical. Outros fatores, como alta paridade, uso prolongado de contraceptivos orais e tabagismo, podem influenciar no desenvolvimento dessa moléstia. Habitualmente, a infecção por HPV acomete jovens no início da atividade sexual, sendo um fenômeno transitório em cerca de $80 \%$ dos casos. Uma pequena fração, em mulheres, apresenta persistência da infecção, provavelmente por falha nos mecanismos imunológicos, o que leva a alterações no epitélio cervical e transformações malignas (PINTO; BARBOSA; PAIVA, 2012).

Outras doenças ocasionadas por microrganismos podem afetar a saúde da mulher, principalmente as infecções vaginais. As mais comuns são da espécie de Trichomonas vaginalis e Gardnerella vaginalis e a Candida albicans, causadora da candidíase vaginal, uma doença muito comum, uma vez que, quase todas as mulheres experimentam esse quadro genital pelo menos uma vez em algum momento de suas vidas (FERRAZZA et al., 2005), sendo, portanto, a espécie de maior importância nas infecções vaginais. A melhor maneira de combater as doenças é por meio de campanhas de prevenção, visando à conscientização e, consequentemente a adoção de hábitos menos prejudiciais. As ações preventivas devem se iniciar na infância, sendo uma responsabilidade social e não apenas governamental (BRENNA et al., 2001).

Quando diagnosticado em sua fase inicial, o câncer de colo de útero possui quase $100 \%$ de chances de cura. O diagnóstico pode ser realizado por meio de técnicas simples e de baixo custo, como o exame de Papanicolaou, que pode ser realizado em postos ou unidades de saúde e em consultórios particulares por profissionais capacitados (INSTITUTO NACIONAL DE CÂNCER, 2010). O exame citológico de Papanicolaou é o método de excelência na avaliação do grau de alteração celular do epitélio escamoso cervical e tem auxiliado na diminuição da incidência do câncer de colo uterino. Para a classificação dos resultados dos exames, vários sistemas de nomenclatura podem ser utilizados (GLASSMAN; BOUILLON, 2007).

O sistema de Bethesda é o mais utilizado, classificando as anormalidades do epitélio escamoso cervical em: lesão de baixo grau (LIBG), lesão de alto grau (LIAG), 
atipias celulares de significado indeterminado (ASCUS) e carcinoma invasor (TUON et al., 2002). No esfregaço cervical, podem ser observadas células que descamam espontaneamente das superfícies do colo e da vagina, acumulando-se no fundo-desaco vaginal posterior, de onde são removidas. Esse método apresenta boa representatividade de células e maior probabilidade de detecção de tumores ocultos do endométrio, tubas e ovários e lesões metastáticas, porém deve-se levar em conta a não conservação celular e a não detecção de lesões pré-cancerosas e cancerosas da cérvice uterina. Já, o esfregaço cervical consiste na remoção de células da superfície da ectocérvice e endocérvice uterina, apresentando grande número de detecções de lesões do canal endocervical, porém exige prática e destreza manual do coletor da amostra (TUON et al., 2002). O número de novos casos de câncer de colo uterino aumenta, gradativamente, todo ano, por isso a necessidade do Ministério da Saúde de implementar ações de controle a esse câncer, que contenham o procedimento padronizado e qualidade, proporcionando, assim, condutas que garantam a qualidade do atendimento (NASCIMENTO; VARGA, 2008).

Este trabalho teve como objetivo desenvolver um estudo de rastreamento do câncer de colo uterino pelo exame de Papanicolaou e microbiológico no Centro de Práticas Supervisionadas (CPS) da UNIVAP, orientando as voluntárias sobre a saúde da mulher, explicando sobre os exames e a importância dos cuidados e prevenção desse tipo de câncer.

\section{METODOLOGIA}

Este estudo foi realizado no Centro de Práticas Supervisionadas (CPS) da Faculdade de Ciências da Saúde, do Campus Urbanova, da Universidade do Vale do Paraíba - UNIVAP, em São José dos Campos, São Paulo. Todo preparo e análise das amostras foram realizados no Núcleo de Estudos Farmacêuticos e Biomédicos (NUFABI), da mesma instituição. Este projeto foi submetido e aprovado pelo Comitê de Ética sob o protocolo 067/2011-PH/CEP e segue as diretrizes e normas regulamentadoras de pesquisas envolvendo seres humanos da resolução 196/96.

O rastreamento foi realizado, inicialmente, em 20 voluntárias selecionadas por meio da análise de prontuários médicos do CPS, com autorização concedida pela Enfermeira responsável e pela diretora da instituição.

As voluntárias foram encaminhadas ao CPS onde receberam informações a cerca do projeto e foram realizadas as suas anamneses. As coletas de material, para os exames, foram realizadas em sala adequada, seguindo os padrões e normas de biossegurança de acordo com as especificações da Anvisa (Resolução - RDC nำ50, de 21 de fevereiro de 2002). A sala apresentava piso e paredes laváveis, iluminação adequada, maca, escada de dois degraus, local adequado para descarte, bancada para separar todo o material necessário para a coleta. 
Inicialmente, foi preenchida uma ficha de coleta com todas as informações referentes aos dados pessoais e dados de coleta de cada voluntária. Em seguida, iniciou-se a coleta do exame ginecológico, que foi realizada com a introdução de um espéculo vaginal seguida da escamação ou esfoliação da ectocérvice e da endocérvice, usando a espátula de Ayres e uma escova endocervical, como mostra a Figura 1.

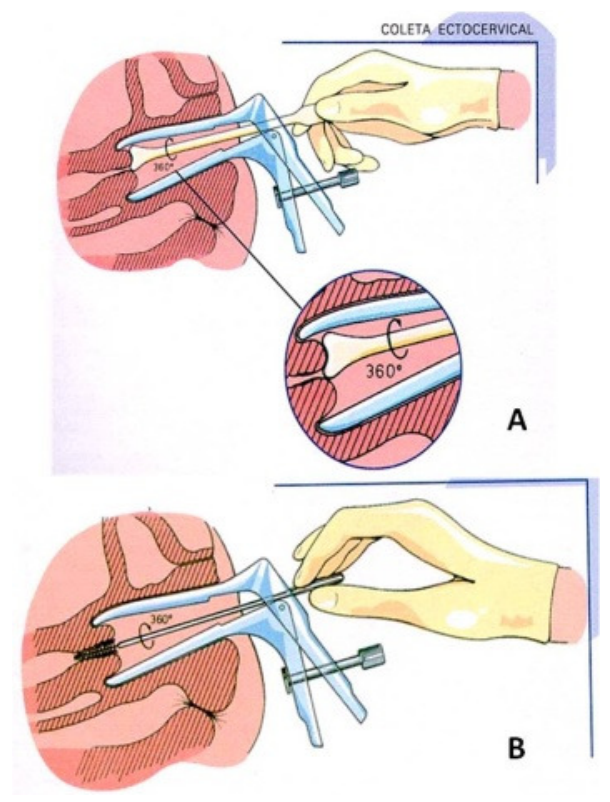

Figura 1 - Procedimento de coleta da região ectocervical (A) e endocervical (B).

Fonte: LABPAC (2012).

O material coletado para análise do Papanicolaou foi fixado imediatamente na lâmina, utilizando-se um fixador em spray, sendo a lâmina corretamente identificada, como apresentado na Figura 2.
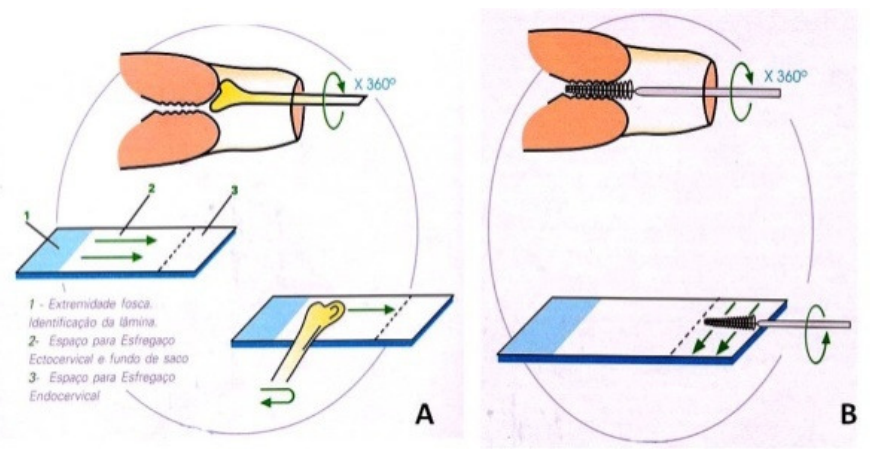

Figura 2 - Procedimento de preparo e fixação do material coletado na lâmina. (A) 0 material ectocervical foi disposto no sentido vertical ou horizontal, ocupando $2 / 3$ da parte transparente da lâmina, em movimento de ida e volta, esfregando a espátula com suave pressão, garantindo uma amostra uniforme. (B) Ocupando o 1/3 restante da lâmina, o material foi estendido rolando a escova de cima para baixo.

Fonte: SÃo PAULO (2006, p. 39). 
Para realização da coloração de Papanicolau, foram utilizados três corantes: Hematoxilina, OG-36 e EA-36 ou EA-65.

Para confecção das lâminas, utilizou-se Entellan® e, após a secagem das lâminas, foram realizadas as leituras em microscópio.

O esfregaço normal deve apresentar células basais, células superficiais e células intermediárias. As amostras anormais foram classificadas de acordo com o sistema de Bethesda.

A secreção, para o exame microbiológico, foi colhida com swab em solução fisiológica a $0,9 \%$ e colocada em estufa a $37^{\circ} \mathrm{C}$ para o exame direto a fresco e para coloração pela técnica de Gram. Em seguida, no caso da amostra positiva, foram realizadas culturas para isolamento e identificação dos microrganismos, utilizando-se meio de ágar Sabouraud. Após incubação em estufa a $37^{\circ} \mathrm{C}$ por 24 horas, as amostras foram observadas e anotadas e em seguida, foi realizada a identificação do microrganismo por meio de microscopia, dependendo dos resultados obtidos, seguindo o protocolo de identificação do Laboratório de Microbiologia, do NUFABI, da Faculdade de Ciências da Saúde.

\section{RESULTADOS E DISCUSSÃO}

Os esfregaços cervicais foram coletados de 12 pacientes, das 20 selecionadas, com idade entre 20 e 60 anos. Os materiais coletados foram armazenados e preparados para análise citológica e microbiológica.

Analisando as amostras coletadas, foram observadas alterações citológicas leves com quadro inflamatório (Tabela 1).

Tabela 1 - A análise citológica do esfregaço cervical de cada voluntária

\begin{tabular}{|c|c|c|c|c|c|c|c|c|c|c|c|c|c|}
\hline \multicolumn{2}{|c|}{ Análises } & \multicolumn{12}{|c|}{ Paciente } \\
\hline & & 1 & 2 & 3 & 4 & 5 & 6 & 7 & 8 & 9 & 10 & 11 & 12 \\
\hline \multirow{3}{*}{ Hormonal } & Estrogênico & $x$ & $x$ & & $x$ & & & & & $x$ & & & \\
\hline & Progesterônico & & & $x$ & & $x$ & $x$ & $x$ & $x$ & & & & \\
\hline & Hipertrófico & & & & & & & & & & $x$ & $x$ & $x$ \\
\hline \multirow{8}{*}{$\begin{array}{l}\text { Citopatológica } \\
\text { (tipos celulares) }\end{array}$} & Superficiais & $\begin{array}{l}++ \\
+\end{array}$ & $\begin{array}{l}++ \\
+ \\
\end{array}$ & + & $\begin{array}{l}++ \\
+ \\
\end{array}$ & + & + & + & + & $\begin{array}{l}++ \\
+ \\
\end{array}$ & + & - & - \\
\hline & Intermediárias & ++ & ++ & $\begin{array}{l}++ \\
+ \\
\end{array}$ & ++ & $\begin{array}{l}++ \\
+ \\
\end{array}$ & $\begin{array}{l}++ \\
+ \\
\end{array}$ & $\begin{array}{l}++ \\
+ \\
\end{array}$ & $\begin{array}{l}++ \\
+ \\
\end{array}$ & + & + & + & + \\
\hline & Parabasais & + & - & + & - & + & + & - & - & ++ & ++ & $\begin{array}{l}++ \\
+ \\
\end{array}$ & ++ \\
\hline & Metaplásicas & $\mathrm{P}$ & $\mathrm{P}$ & $\mathrm{P}$ & - & - & $\mathrm{P}$ & - & - & $P$ & $\mathrm{P}$ & $P$ & $\mathrm{P}$ \\
\hline & Endocervicais & $\mathrm{P}$ & - & $\mathrm{P}$ & $\mathrm{P}$ & $\mathrm{P}$ & $\mathrm{P}$ & - & $\mathrm{P}$ & $\mathrm{P}$ & - & $P$ & $\mathrm{P}$ \\
\hline & Histiócitos & - & - & - & - & - & - & - & - & - & - & - & - \\
\hline & Polimorfonucleares & - & $\mathrm{P}$ & - & $\mathrm{P}$ & $P$ & $P$ & $P$ & $P$ & $P$ & $P$ & - & + \\
\hline & Eritrócitos & - & - & - & - & - & - & - & - & - & - & $\mathrm{P}$ & - \\
\hline
\end{tabular}

(+ raras; ++ moderadas; +++ abundantes; - ausentes; $\mathrm{P}$ presentes) 
Uma paciente foi diagnosticada com alterações de células escamosas de significado indeterminado. Na análise microbiológica (Tabela 2), observou-se, em 6 pacientes, a presença de leveduras por meio da microscopia, não sendo realizados testes para identificação de Candida sp. e ausência de Trichomonas vaginalis (Figura 3).

\section{Análise Microbiológica}

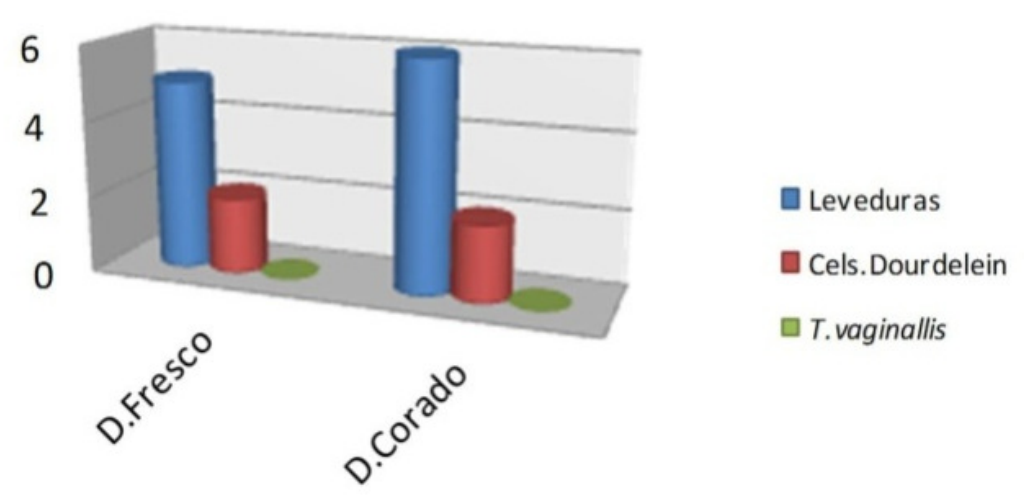

Figura 3 - Resultados da análise microbiológica, evidenciando maior eficácia do exame corado, na identificação de leveduras.

Tabela 2 - Bacterioscopia - Exame direto a fresco e corado. Avaliação, por meio do esfregaço cervical, para identificação de microrganismos e presença de células inflamatórias

\begin{tabular}{|c|c|c|c|c|c|c|c|}
\hline & \multicolumn{7}{|l|}{ Paciente } \\
\hline & & 1 & 2 & 3 & 6 & 7 & 8 \\
\hline \multirow{4}{*}{ Fresco } & Leucócitos & + & + & ++ & + & + & + \\
\hline & Céls. Epiteliais & + & + & ++ & + & ++ & ++ \\
\hline & Leveduras & $P$ & + & - & $\mathrm{P}$ & $\mathrm{P}$ & $P$ \\
\hline & T. vaginalis & - & - & - & - & - & - \\
\hline \multirow{4}{*}{ Corado } & Leucócitos & + & + & ++ & + & + & + \\
\hline & Céls. Epiteliais & + & + & ++ & + & ++ & ++ \\
\hline & Leveduras & $P$ & + & $P$ & $\mathrm{P}$ & $P$ & $\mathrm{P}$ \\
\hline & T. vaginalis & - & - & - & - & - & - \\
\hline \multicolumn{2}{|l|}{ Cultura para fungos } & $x$ & $x$ & $x$ & $\mathrm{x}$ & $x$ & $x$ \\
\hline \multicolumn{2}{|l|}{ Células de Dourderlain } & $x$ & - & - & - & - & $\mathrm{x}$ \\
\hline
\end{tabular}

Após as análises dos resultados, as voluntárias foram comunicadas e as que apresentaram alterações nos resultados dos exames foram encaminhadas a um médico ginecologista. Todas as voluntárias receberam instruções sobre a importância do exame 
preventivo.

Segundo a literatura, há uma correlação entre o ciclo hormonal da mulher e a presença de células escamativas, sendo observada uma grande quantidade de células superficiais na fase estrogênica, com diminuição dessas e aumento das células intermediárias na fase progesterônica (KOSS; GOMPEL, 2006), que pode ser evidenciado ao se comparar a Tabela 1 com as Figuras 4 e 5.

\title{
Análise hormonal
}

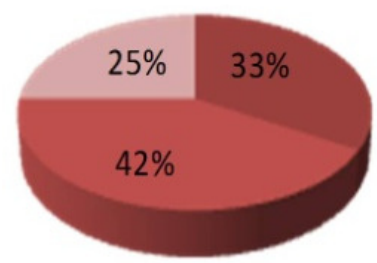

\author{
Estrogenico \\ Progesteronico \\ Hipertrofico
}

Figura 4 - Análise Hormonal, evidenciando $42 \%$ das pacientes em fase progesterônica.

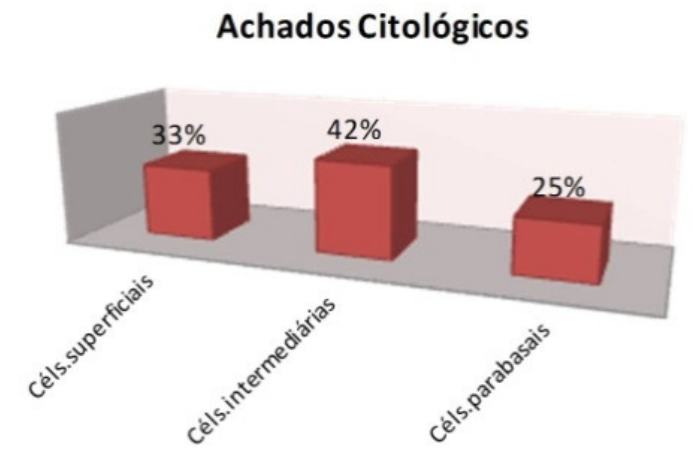

Figura 5 - Achados Citológicos com $42 \%$ de ocorrência de células intermediárias, $33 \%$ de células superficiais e $25 \%$ de células parabasais.

Com a análise citológica, foi possível observar que $58 \%$ das pacientes possuem indícios de inflamação leve, sendo $8 \%$ dessas com um resultado positivo para ASCUS (Alterações de Células Escamosas de resultado Indeterminado), e apenas 34\% das voluntárias apresentaram resultado normal (Figura 6). 


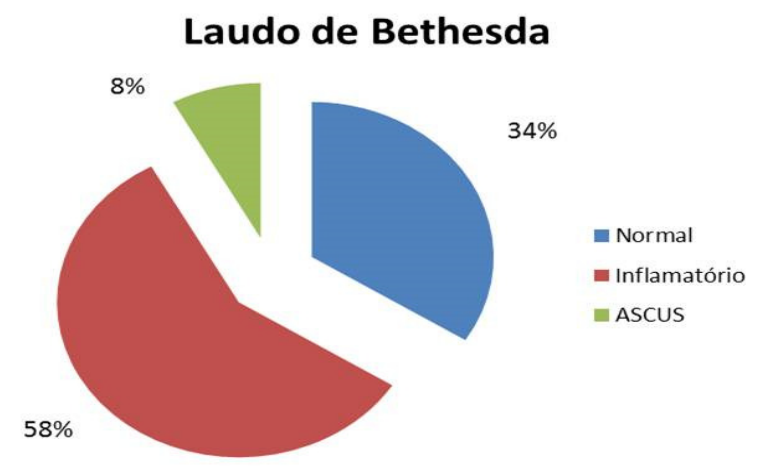

\section{Figura 6 - Resultados do Laudo de Bethesda, evidenciando $58 \%$ de pacientes com indícios de inflamação leve.}

Mesmo com um número pequeno de amostras, nota-se que a presença de pacientes com processo inflamatório é superior ao resultado normal, o que indica a necessidade de prevenção e divulgação do exame citológico.

Este estudo demonstrou os benefícios e a importância da saúde da mulher, bem como as vantagens da conscientização sobre o exame preventivo.

Por vezes, o Sistema Único de Saúde (SUS) não possui recursos para tender o grande número de pacientes, deixando parte da população feminina sem o acesso à realização do exame de Papanicolaou. Além disso, a demora em se marcar uma consulta acaba comprometendo a principal função do exame, que é a prevenção, o que leva ao desenvolvimento de lesões graves na região uterina, que seriam facilmente evitadas por meio da realização do exame e tratamento adequado.

\section{CONCLUSÃO}

A análise microbiológica evidenciou predominância de leveduras, e os achados citopatológicos evidenciaram uma amostra com alterações leves com quadro inflamatório e um quadro com células escamosas de significado indeterminado. Sugerese a criação de um programa para a conscientização da importância do exame de Papanicolaou e sua implantação no Núcleo de Práticas Supervisionadas (CPS), com a finalidade de disponibilizar um serviço de rastreamento do câncer cervical, a fim de promover a prevenção, diagnóstico e tratamento do câncer de colo de útero, para os funcionários da Universidade e pacientes do CPS.

\section{REFERÊNCIAS}

PINOTTI, J. A. A mulher conhecendo sua saúde. São Paulo: Secretaria de Estado de Saúde de SP, 1994. 
BRENNA, S. M. F. et al. Conhecimento, atitude e prática do exame de Papanicolaou em mulheres com câncer de colo uterino. Cadernos de Saúde Pública, v. 17, n. 4, pp. 909914, 2001.

FERRAZZA, M. H. S. H. et al. Caracterização de leveduras isoladas da vagina e sua associação com candidíase vulvovaginal em duas cidades do sul do Brasil. Revista Brasileira de Ginecologia e Obstetrícia, v. 25, n. 2, pp. 58-63, 2005.

GLASSMAN, A.; BOUILLON, C. P. La protección social en salud al frente de las políticas de reducción de la pobreza. Salud pública México, v. 49, n. 1, p. 512-513, 2007.

HACKENHAAR, A. A.; CESAR, J. A.; DOMINGUES, M. R. Exame citopatológico de colo uterino em mulheres com idade entre 20 e 59 anos em Pelotas, RS: prevalência, foco e fatores associados à sua não realização. Revista Brasileira de Epidemiologia, v. 9, n. 1, mar. $2006 . \quad$ Disponível em: $<$ http://www.scielo.br/scielo.php?script=sci arttext\&pid=S1415-

790X2006000100013\&lng=en\&nrm=iso >. Acesso em: 14 maio 2014. http://dx.doi.org/10.1590/S1415-790X2006000100013.

KOSS, L. G.; GOMPEL, C. Introdução à citopatologia ginecológica com correlações histológicas e clínicas. São Paulo: Roca, 2006.

INSTITUTO NACIONAL DE CÂNCER (Brasil). Estimativa 2010 da Incidência de câncer no Brasil. Rio de Janeiro: INCA, 2010. Disponível em: < http://www2.inca.gov.br/wps/wcm/connect/agencianoticias/site/home/noticias/2009/lanc amento estimativa 2010>. Acesso em: $21 \mathrm{fev} .2011$.

LABPAC. LABORATÓRIO ESPECIALIZADO EM ANATOMIA PATOLÓGICA E CITOLOGIA. Manual de Coleta de Citologia Cérvico Vaginal. 2. ed. São Paulo, set. $2012 . \quad$ Disponível em: <http://www.labpac.com.br/labpac/var/arquivos/docs/MANUAL DE COLETA.pdf>.

Acesso em: 12 set. 2012.

NASCIMENTO, V. T.; VARGA, V. R. A. Frequência de citologias atípicas no Laboratório Oswaldo Cruz, município de Santo Angelo-RS. Revista Brasileira de Farmácia, v. 89, n. 4, pp. 347-351, 2008.

PINTO, V. F. C.; BARBOSA, V. F. C.; PAIVA, S. G. Aspectos epidemiológicos e citológicos de infecções pelo papilomavírus humano (HPV) em adolescentes: Uma revisão, Revista Científica ITPAC, Araguaína, v. 5, n. 4, 2012.

RAMA, C. H. et al. Prevalência do HPV em mulheres rastreadas para o câncer cervical. Rev. Saúde Pública, São Paulo, v. 42, n. 1, fev. 2008. Disponível em: $<$ http://www.scielo.br/scielo.php?script=sci arttext\&pid=S0034-

89102008000100016\&lng=en\&nrm=iso>. Acesso em: 14 maio 2014. http://dx.doi.org/10.1590/S0034-89102008000100016. 
TUON, F. F. B. et al. Avaliação da sensibilidade e especificidade dos exames citopatológico e colposcópico em relação ao exame histológico na identificação de lesões intra-epiteliais cervicais. Revista Assoc. Med., v. 28, n. 2, pp. 140-144, 2002.

SÃO PAULO (Cidade). Secretaria da Saúde. Manual técnico: normatização das rotinas e procedimentos de enfermagem nas Unidades Básicas de Saúde. São Paulo: SMS, 2006. Disponível em: <http://www.prefeitura.sp.gov.br/cidade/secretarias/upload/saude/arquivos/enfermage m/ManualTecnico NormasRotinas 2009.pdf>. Acesso em: 14 maio 2014.

WORLD HEALTH ORGANIZATION. Health Topics. 2006. Disponível em: <www.who.int/topics>. Acesso em: 26 nov. 2006. 